\title{
Theoretical Characterization of Steady-state Heat Wave Propagating in Iron Ore Sintering Bed
}

\author{
Masanori NAKANO, Kazuaki KATAYAMA and Shunji KASAMA \\ Environment \& Process Technology Center, Nippon Steel Corporation, 20-1 Shintomi, Futtsu, Chiba $293-8511$ Japan.
}

(Received on July 22, 2009; accepted on December 2, 2009)

\begin{abstract}
Knowledge of heat wave is a key to control the iron ore sintering process. To enhance the knowledge, numerical integration of differential equations for gas and solid is prevailing; this report, otherwise, used an analytical method and introduced several solutions by the assumption that the heat wave descended in steady state and that gas and solid temperatures coincided. The solutions correlated characters of heat wave with operational factors in a simple and explicit manner like:

1) Heat behind speed $\left(U_{B}\right)$ was a function of gas velocity $\left(u_{g}\right)$ as $U_{B}=\left(c_{g} u_{g}\right) /\left(c_{s} \rho_{s}\right)$;

2) Solid maximum temperature $\left(T_{p}\right)$ comprised an adiabatic temperature increase due to coke combustion $(\theta c)$ and a heat convection due to downdraft necessary for solid temperature to heat up to coke ignition ( $\theta i g)$ as $T_{\mathrm{p}}=\theta c+\theta i g$;

3) Heat front speed $\left(U_{F}\right)$ correlated with $U_{B}(=v)$ and the terms for coke combustion heat generation $(\theta c)$ and ignition temperature $(\theta i g)$ as $U_{\mathrm{F}}=v \cdot(1+\theta c / \theta i g)$.

KEY WORDS: agglomeration; flame front speed; heat behind speed; heat wave; iron ore sintering; maximum temperature; steady state.
\end{abstract}

\section{Introduction}

Iron ore sintering proceeds with heat wave descending across sintering bed due to heat generation by coke breeze combustion and heat transfer by down draft. The heat wave is one of major controllers for the process as it governs the amount and active duration of liquid phase that bonds raw material particles to massive sinter. The sintering operation will improve with firm knowledge on the heat wave, specifically on the flame front speed $\left(U_{\mathrm{F}}\right)$, heat behind speed $\left(U_{\mathrm{B}}\right)$ and the maximum temperature of bed $\left(T_{\mathrm{P}}\right)$.

Experimental works emerged early in the sintering history: Voice et al. ${ }^{1)}$ examined behavior of heat wave for a simplified system, coke and balls of inert materials instead of iron ore particles, and pointed out the importance of matching coke combustion and heat transfer. Sanbongi et $a l^{2,3)}$ measured the effect of various factors on heat wave by pot test (analogous sintering experiment).

Theoretical studies derived from a couple of differential equations describing heat balance for solid (Eq. (i) in Table

Table 1. Basic differential equations describing heat wave propagation in sintering bed. ${ }^{4)}$
1) and gas (Eq. (ii)) with a rate equation for coke combustion (Eq. (iii)): Muchi et al. ${ }^{4)}$ applied a numerical method with the aid of computer and realized heat wave analysis. Suffering with unstable excursion, maybe caused by exponential behavior of coke combustion, the method prevailed over Japan in 1970's in success to explain the experimental facts and to estimate the effect of operational factors. Nevertheless, it might have failed to increase our principal understanding of the phenomena.

Analytical approaches stand on the assumption that gas and solid temperatures agree, which gives a unique equation (Eq. (iv)): Block ${ }^{5)}$ obtained an analytical solution for the equation; his solution still has an integration term that needs numerical calculation. Wajima et $a l^{6)}$ showed a fast calculation method by assuming an exponential type curve for heat behind and allowing overall heat balance to decide $T_{\mathrm{P}}$; their method still needed an empirical relationship between gas velocity and cooling speed.

Simple and explicit equations linking sintering operational factors to heat wave's characters will be available for direct understanding of the phenomena as well as for design and practice of sintering operation. Horio et $a l^{7)}$ showed the existence of steady-state propagation for well-developed heat wave and lead equations for $U_{\mathrm{F}}, U_{\mathrm{B}}$ and $T_{\mathrm{P}}$ under the condition; unfortunately, their equations needed some computer calculation, for they treated gas and solid temperature separately.

The steady-state assumption for heat wave seems potent; then, adding the assumption of gas-solid temperature coincidence and applying heat balance for each zone of steady- 
state heat wave, we will show simple, directly understandable, if not strict, equations describing heat wave's characters.

\section{Equations for $U_{\mathrm{F}}, U_{\mathrm{B}}$ and $T_{\mathrm{P}}$}

\subsection{Triangle Heat Wave}

We will start with a heat wave of simple shape that the third clause defines below. Assumptions are:

1) Heat exchange is quick enough for gas and solid temperatures to coincide.

2) There exists steady-state propagation of heat wave.

3) As shown in Fig. 1, where the horizontal axis, $z$, means the distance from surface and the vertical axis, $T$, means the solid (bed) temperature defined based on the ambient one $\left(T_{0}=0\right)$, the heat wave has triangle shape: In heat front zone (HF) the temperature increases to the maximum $\left(T_{\mathrm{P}}\right)$ straightly; in heat behind zone (HB) the temperature decreases straightly to the ambient temperature at the surface. The HF moves at a constant speed $\left(U_{\mathrm{F}}\right)$, keeping the maximum temperature at a constant value $\left(T_{\mathrm{P}}\right)$.

Comparing the heat waves before and after moving for an incremental distance $(\Delta z)$ (Fig. 1) tells that the increase of heat accumulation in $\mathrm{HB}$ is $c_{\mathrm{s}} \rho_{\mathrm{s}}\left(A \Delta z T_{\mathrm{P}}\right) / 2$ with a geometric consideration. The corresponding heat generation for the moment is $A \Delta z Q$. They are equal, which gives Eq. (1) with use of a parameter, $\theta$, for $Q /\left(c_{s} \rho_{\mathrm{s}}\right)$ :

$$
T_{\mathrm{P}}=2 \theta c
$$

where

$T_{\mathrm{P}}$ : the maximum temperature of solid on ambient basis $(\mathrm{K})$

$c_{\mathrm{s}}:$ heat capacity of solid $(\mathrm{J} / \mathrm{kg} / \mathrm{K})$

$\rho_{\mathrm{s}}$ : bulk density of solid $\left(\mathrm{kg} / \mathrm{m}^{3}\right)$

$Q:$ calorific value per unit volume $\left(\mathrm{J} / \mathrm{m}^{3}\right)$

$\theta c: \quad=Q /\left(c_{\mathrm{s}} \rho_{\mathrm{s}}\right)(\mathrm{K})$

$A:$ area $\left(\mathrm{m}^{3}\right)$

$\Delta z:$ an incremental distance $(\mathrm{m})$.

Wendeborn $^{8)}$ has already reached to the same result with another method, which Shimomura ${ }^{9)}$ introduced to Japan in his review as the first theoretical approach in the field.

Figure 2 shows a heat balance through HF with use of the coordinate moving at the speed of $U_{\mathrm{F}}$ along $z$-axis in

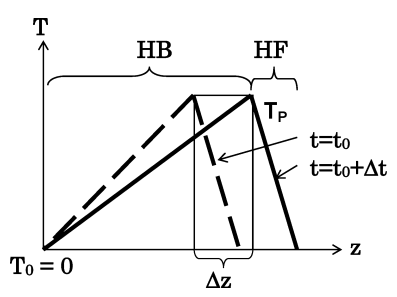

Fig. 1. Triangle heat wave before and after moving by $\Delta z$ for $\Delta t$.

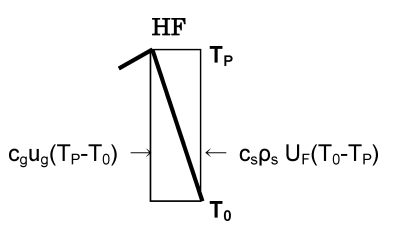

Fig. 2. Heat balance through heat front zone. synclonization with HF. In terms of heat flux $\left(\mathrm{J} / \mathrm{m}^{2}\right)$, solid brings 0 and takes $c_{\mathrm{s}} \rho_{\mathrm{s}} U_{\mathrm{F}} T_{\mathrm{P}}$; gas brings $c_{\mathrm{g}} u_{\mathrm{g}} T_{\mathrm{P}}$ and takes 0 ; coke generates $Q U_{\mathrm{F}}$. The sum of them has to be zero, which makes:

$$
c_{\mathrm{s}} \rho_{\mathrm{s}} U_{\mathrm{F}} T_{\mathrm{P}}=c_{\mathrm{g}} u_{\mathrm{g}} T_{\mathrm{P}}+Q U_{\mathrm{F}}
$$

where

$c_{\mathrm{g}}$ : heat capacity of gas in volume basis $\left(\mathrm{J} / \mathrm{m}^{3} / \mathrm{K}\right)$

$u_{\mathrm{g}}:$ gas velocity $(\mathrm{m} / \mathrm{s})$

$U_{\mathrm{F}}$ : heat front speed $(\mathrm{m} / \mathrm{s})$.

Substituting $2 Q /\left(c_{\mathrm{s}} \rho_{\mathrm{s}}\right)$ for $T_{\mathrm{P}}(=2 \theta c)$ and using a parameter, $v$, for $\left(c_{\mathrm{g}} u_{\mathrm{g}}\right) /\left(c_{\mathrm{s}} \rho_{\mathrm{s}}\right)$, then

$$
U_{\mathrm{F}}=2 v
$$

where

$$
v:=\left(c_{\mathrm{g}} u_{\mathrm{g}}\right) /\left(c_{\mathrm{s}} \rho_{\mathrm{s}}\right)(\mathrm{m} / \mathrm{s})
$$

\subsection{Trapezoidal Heat Wave with Infinite Coke Com- bustion Rate}

To obtain equations including some parameters that characterize coke combustion properties and an equation for $U_{\mathrm{B}}$, we will restart with assuming another shape for the heat wave (Fig. 3).

1) Heat wave has a trapezoidal shape consisting of HF, TOP and HB. HF corresponds to preheating zone of solid. The solid holds at the maximum temperature after coke combustion, the part is named TOP, followed by HB where the cooling speed of solid is assumed constant.

2) Coke burns from a given ignition temperature $(\theta i g)$ at infinite rate, giving out a given heat $(Q)$.

Obviously, $T_{\mathrm{P}}$ becomes the sum of $\theta i g$ and $\theta c$; namely,

$$
T_{\mathrm{P}}=\theta c+\theta i g
$$

where $\theta i g$ : ignition temperature of coke $(\mathrm{K})$.

Making a heat balance through HF in the same way as Eq. (2) is derived shows that solid takes $c_{\mathrm{s}} \rho_{\mathrm{s}} U_{\mathrm{F}} \theta i g$; gas brings $c_{\mathrm{g}} u_{\mathrm{g}} T_{\mathrm{p}}$; no coke combustion. Equaling them and substituting $(\theta c+\theta i g)$ for $T_{\mathrm{P}}$,

$$
U_{\mathrm{F}}=v(1+\theta c / \theta i g)
$$

Making another heat balance through HB shows that solid takes $c_{\mathrm{s}} \rho_{\mathrm{s}} U_{\mathrm{B}} T_{\mathrm{P}}$; gas brings $c_{\mathrm{g}} u_{\mathrm{g}} T_{\mathrm{P}}$; no coke combustion. Thus,

$$
U_{\mathrm{B}}=v
$$

\subsection{Trapezoidal Heat Wave with a Finite Coke Com- bustion Rate}

When coke burns at a finite rate (Fig. 4), HF will divide into two zones: drying and combustion zones. Heat balance through the drying zone gives: $U_{\mathrm{F}}=v$. Thus,

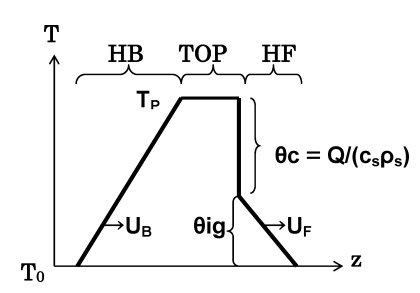

Fig. 3. Trapezoidal heat wave with infinite coke combustion rate. 


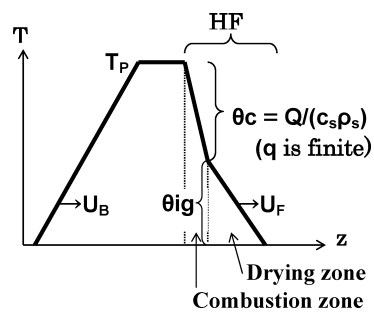

Fig. 4. Trapezoidal heat wave with a finite coke combustion rate, $q$.

$$
U_{\mathrm{F}}=U_{\mathrm{B}}(=v)
$$

This solution is inevitable but undesired.

\subsection{Triangle Heat Wave Having Temperature Differ- ence between Solid and Gas}

For obtaining $U_{\mathrm{F}}$ faster than $v$, we will shift closer to the fact, namely discard the first assumption that $T s=T g$ and assume $T g>T s$ in HF.

1) Start with triangle heat wave like Sec. 2.1 for simplicity.

2) Coke burns from an ignition temperature $(\theta i g)$ at a finite rate, emitting heat $Q$.

3) $T g=T s$ in $\mathrm{HB}$ as well; $T g>T s$ in HF.

The triangle heat wave gives: $T_{\mathrm{P}}=2 \theta c$, as is shown for Eq. (1).

Letting $T s_{\text {ig }}$ and $T g_{\text {ig }}$ designate solid and gas temperature at the interface between drying and combustion zones, respectively, then solid gets $c_{\mathrm{s}} \rho_{\mathrm{s}} T s_{\mathrm{ig}} U_{\mathrm{F}}$; gas loses $c_{\mathrm{g}} u T g_{\mathrm{g}}$ as heat flux through drying zone. Thus,

$$
U_{\mathrm{F}}=v\left(T g_{\text {ig }} / T s_{\text {ig }}\right)
$$

Through combustion zone, solid gets $c_{\mathrm{s}} \rho_{\mathrm{s}}\left(T_{\mathrm{P}}-T s_{\mathrm{ig}}\right) U_{\mathrm{F}}$; gas loses $c_{\mathrm{g}} u_{\mathrm{g}}\left(T_{\mathrm{P}}-T g_{\mathrm{ig}}\right)$, coke generates $Q U_{\mathrm{F}}$. Taking heat balance, and putting $2 \theta c$ for $T_{\mathrm{P}}$ and $v\left(T g_{\mathrm{ig}} / T s_{\mathrm{ig}}\right)$ for $U_{\mathrm{F}}$,

$$
T g_{\text {ig }}=2 T s_{\text {ig }}
$$

Combining Eqs. (6) and (7) gives $U_{\mathrm{F}}=2 v$, suggesting that $U_{\mathrm{F}}$ is independent on whether gas and solid temperatures are same or not. The assumption of triangle heat wave may give strong restriction to the solution for $U_{\mathrm{F}}$.

Assuming more complicated shapes for heat wave, we tried to build a finite coke combustion rate $(q)$ and a combustion duration $(\tau)$ into the expression for $U_{\mathrm{F}}$. However any trial failed so far with the result that they appeared in the form of $\tau \times \theta(=Q)$ anytime.

\subsection{Interpretation of the Equations Describing $T_{\mathrm{P}}, U_{\mathrm{F}}$ and $U_{\mathrm{B}}$}

2.4.1. Maximum Temperature $\left(T_{\mathrm{P}}\right)$

The parameter $\theta c$ means an adiabatic temperature increase due to coke combustion. It partly contributes to make up $T_{\mathrm{P}}$. The other contributor is downward heat transfer by airflow.

Equation (1) shows rough contributions of the two factors; they are half and half.

Equation (3) adds more information that the magnitude of heat transfer contribution meets the heat necessary for solid temperature to elevate up to the coke ignition temperature, suggesting:
- Increase in coke content, use of low CW ores and heat generating materials, such $\theta c$-increasing actions allow the $T_{\mathrm{P}}$ to increase;

- Increase in oxygen content, use of high reactivity coke, size down of coke diameter; such $\theta$ ig-decreasing actions decrease the $T_{\mathrm{P}}$.

\subsubsection{Heat Behind Speed $\left(U_{\mathrm{B}}\right)$}

Many researchers have already proven that $v$ coincides to heat behind speed, or the heat wave speed without coke combustion. ${ }^{10)}$ We have confirmed it with Eq. (5).

\subsubsection{Heat Front Speed $\left(U_{\mathrm{F}}\right)$}

Equation (2) predicts without explanation that the HF moves twice as quickly as HB.

Equation (4) gives a more reasonable explanation on the phenomena: the speed gain of HF from that of HB is governed by the ratio of heat generation, most of which coke generates, to coke's ignition temperature. The Eq. (4) suggests:

- Increase in gas velocity and gas heat capacity raise HF speed in conjunction with $v$;

- The $\theta$ ig-decreasing actions result in the increase in HF speed;

- The $\theta c$-increasing actions lead to the increase in HF speed.

Equation (6) highlights another aspect of the phenomena. The other driving force of heat wave, except for gas velocity, is the temperature difference between solid and gas. The ratio of gas's temperature to solid's one determines the displacement of HF speed from $v$ according to the equation. As a matter of fact, the difference won't be detective; otherwise the equation can be available to estimate the difference based on measured $U_{\mathrm{F}}$.

\section{Validation of Equations}

\subsection{Heat Front Speed $\left(U_{\mathrm{F}}\right)$}

To validate the equations derived for $U_{\mathrm{F}}$, we will use the typical values for the constants: $c_{\mathrm{g}}=1.3 \mathrm{~kJ} / \mathrm{Nm}^{3} / \mathrm{K}, u_{\mathrm{g}}=$ $0.3 \mathrm{Nm} / \mathrm{s}, c_{\mathrm{s}}=0.83 \mathrm{~kJ} / \mathrm{kg} / \mathrm{K}, \rho_{\mathrm{s}}=2000 \mathrm{~kg} / \mathrm{m}^{3}$, and refer to Kawaguchi et al.' 's ${ }^{11)}$ correlations of $U_{\mathrm{F}}$ to $u_{\mathrm{g}}$ :

[Pot test] $\quad U_{\mathrm{F}}(\mathrm{mm} / \mathrm{s})=1.05 u_{\mathrm{g}}(\mathrm{Nm} / \mathrm{s})+0.1$

[Calculation] $U_{\mathrm{F}}(\mathrm{mm} / \mathrm{s})=1.4-1.5 u_{\mathrm{g}}(\mathrm{Nm} / \mathrm{s})$

Order estimation of $U_{\mathrm{F}}$ with Eq. (2) follows:

$U_{\mathrm{F}}(\mathrm{m} / \mathrm{s})=2\left(\left(c_{\mathrm{g}} u_{\mathrm{g}}\right) /\left(c_{\mathrm{s}} \rho_{\mathrm{s}}\right)\right)=2 \times(1.3 / 0.83 / 2000) \times u_{\mathrm{g}}$

$U_{\mathrm{F}}(\mathrm{mm} / \mathrm{s})=1.08 u_{\mathrm{g}}(\mathrm{Nm} / \mathrm{s})$;

Equation (4) offers another estimate:

$$
\begin{aligned}
& U_{\mathrm{F}}(\mathrm{m} / \mathrm{s})=\left(\left(c_{\mathrm{g}} u_{\mathrm{g}}\right) /\left(c_{\mathrm{s}} \rho_{\mathrm{s}}\right)\right)(1+\theta c / \theta i g) \\
& =(1.3 / 0.83 / 2000)(1+576 / 600) \times u_{\mathrm{g}}
\end{aligned}
$$

Both estimates have slight difference and well meet the pot test result. Here has been proven the validity of the equations for $U_{\mathrm{F}}$. 


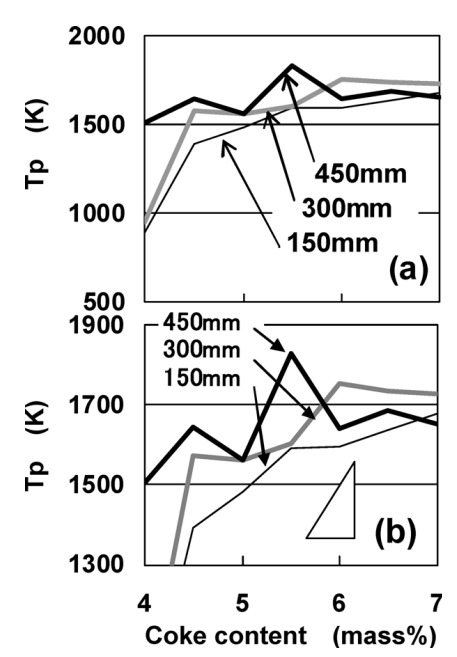

Fig. 5. An experimental result for the maximum temperature of bed with changing coke content. (b) is a close-up for 1300-1900 K range of temperature. The slope of triangle in (b) designates the coefficient, $363(\mathrm{~K} / \mathrm{mass} \%)$, Eq. (8) predicted.

Table 2. Heat sources and calories $\left(\mathrm{kJ} / \mathrm{m}^{3}\right)$.

\begin{tabular}{ll}
\hline Coke combustion & $(+) 2407 \mathrm{MJ} / \mathrm{m}^{3}$ \\
& $=4 \mathrm{mass} \% * 2000 \mathrm{~kg} / \mathrm{m}^{3 *} 7200 \mathrm{kcal} / \mathrm{kg} * 4.18$ \\
Dehydration & $(-) 361 \mathrm{MJ} / \mathrm{m}^{3}$ \\
& $=8 \mathrm{mass} \% * 2000 \mathrm{~kg} / \mathrm{m}^{3 *} 539 \mathrm{kcal} / \mathrm{kg} * 4.18$ \\
Lime Calcination & $(-) 355 \mathrm{MJ} / \mathrm{m}^{3}$ \\
& $=10 \mathrm{mass} \% * 2000 \mathrm{~kg} / \mathrm{m}^{3 *}\left(178.8 \mathrm{~kJ} / \mathrm{mol}^{12)} / 100\right)^{*} 1000$ \\
CF formation & $(+) 15 \mathrm{MJ} / \mathrm{m}^{3}$ \\
& $=10 \mathrm{mass} \%{ }^{*} 2000 \mathrm{~kg} / \mathrm{m}^{3 *}\left(16.7 \mathrm{~kJ} / \mathrm{mol}^{12)} / 216\right)^{*} 1000$ \\
CF melting & $(-) 501 \mathrm{MJ} / \mathrm{m}^{3}$ \\
& $=50 \mathrm{mass} \% * 2000 \mathrm{~kg} / \mathrm{m}^{3 *}\left(108.3 \mathrm{~kJ} / \mathrm{mol}^{12)} / 216\right)^{*} 1000$ \\
\hline Sum & $1205 \mathrm{MJ} / \mathrm{m}^{3}$ \\
\hline
\end{tabular}

\subsection{Maximum Temperature $\left(T_{\mathrm{P}}\right)$}

For $T_{\mathrm{P}}$ validation we investigated the effect of coke content on $T_{\mathrm{P}}$ by pot test, varying coke content from 4.0 to $7.0 \mathrm{mass} \%$ and measuring bed temperatures at the depth of $100 \mathrm{~mm}, 150 \mathrm{~mm}$ and $450 \mathrm{~mm}$ with a standard method using a $300 \mathrm{~mm}$-dia and $600 \mathrm{~mm}$-height pot, a $12 \mathrm{kPa}$-constant suction and a typical ore blend. According to the result (Fig. 5), the maximum temperature at any point increased with increasing coke content; the steady state propagation attained at least at the depth of $450 \mathrm{~mm}$, where the ratio of temperature increase by coke content was between 60 and $200 \mathrm{~K} / \mathrm{mass} \%$; for $300 \mathrm{~mm}$ depth, the state also seemed to establish over 4.5 mass $\%$ coke content with the ratio of increase being approx. $50 \mathrm{~K} / \mathrm{mass} \%$.

$Q$ should reflect not only coke's combustion but also other relevant heat sources' reactions. According to Table 2, the sum of them gives $1205 \mathrm{MJ} / \mathrm{m}^{3}$ to $Q$ at $4 \mathrm{mass} \%$ of coke content. Based on Eq. (3), an estimated maximum temperature at 4 mass $\%$ coke content becomes:

$$
\begin{aligned}
T_{\mathrm{P}}(\mathrm{K}) & =\theta i g+Q /\left(c_{\mathrm{s}} \rho_{\mathrm{s}}\right) \\
& =600+1205000 /(0.83 \times 2000) \\
& =1326(\mathrm{~K})
\end{aligned}
$$

which happens to be close to the observed value.
The differential form of the Eq. (3), can also tell quantitatively a gain in maximum temperature per one mass $\%$ increase of coke content:

$$
\begin{aligned}
d T_{\mathrm{P}} / d(\% \mathrm{C}) & =\left(1 /\left(c_{\mathrm{s}} \rho_{\mathrm{s}}\right)\right) d Q / d(\% \mathrm{C}) \\
& =(1 / 1660) \times 602000 \\
& =363(\mathrm{~K} / \mathrm{mass} \%) \ldots \ldots . .
\end{aligned}
$$

where $(\% \mathrm{C})$ : coke content (mass $\%)$.

The estimated value for the gain stays far from that of experiment. This must be because of neglecting the heat loss due to melting. Modifying the model to involve the melting phenomena will be a further problem.

\subsection{Comparison with the Conventional Muchi Method}

The conventional Muchi method is logically strict, but uneasy to use because of needing time-consuming calculation and yielding results with uncertainty due to unknown parameter and numerical calculation itself, but difficult to understand the cause-effect relation from the dumped results.

The present method has given simple and explicit correlations between cause factors and effects on heat wave, which will ease the understanding of the phenomena. The equations involve coke's ignition temperature $(\theta i g)$ needing individual measurement for coke by coke; contrarily, the Muchi method uses unique coke's property as a combination of chemical reaction rate $(k)$ and activation energy $(E)$. The Muchi's description familiar with reaction engineering seems universal; however, the advantage is superficial because the method pushed the complexity into another parameter of surface area, the evaluation of which requires individual measurement.

Since the measurement for coke ignition temperature is more productive than that for the surface area, the present method offers an alterative industrially preferable to estimate on sintering heat wave. Note that the application is restricted to the well-developed heat wave. The phenomena are out of scope during the ignition and the transient sintering in upper layer.

\section{Concluding Remarks}

Assuming steady-state propagation of heat wave and coincidence of gas-solid temperature and neglecting melting behavior, a set of simple and explicit equations has been introduced, which correlates characters of heat wave with operational factors like:

(1) Heat behind speed $\left(U_{\mathrm{B}}\right)$ was a function of gas velocity $\left(u_{\mathrm{g}}\right)$ as $U_{\mathrm{B}}=\left(c_{\mathrm{g}} u_{\mathrm{g}}\right) /\left(c_{\mathrm{s}} \rho_{\mathrm{s}}\right)$;

(2) Bed maximum temperature $\left(T_{\mathrm{P}}\right)$ comprises an adiabatic temperature increase due to coke combustion $(\theta c)$ and a heat convection due to downdraft necessary for solid temperature to elevate to coke ignition $(\theta i g)$, as $T_{\mathrm{P}}=\theta c+\theta i g$;

(3) Heat front speed $\left(U_{\mathrm{F}}\right)$ correlates to $U_{\mathrm{B}}(=v)$, the heat generation $(\theta c)$, ignition temperature of coke $(\theta i g)$ as $U_{\mathrm{F}}=v(1+\theta c / \theta i g)$.

These equations give good perspective of the operating factors' effect on heat wave characteristics. As for the heat front speed the theoretical and the experimental results 
shows good accordance; but not for the maximum temperature owing to lacking knowledge about melting.

\section{REFERENCES}

1) E. W. Voice and R. Wild: J. Met., (1958), 105.

2) K. Sanbongi, N. Nishida and A. Shuzawa: Tetsu-to-Hagané, 46 (1960), 1527.

3) K. Sanbongi and N. Nishida: Tetsu-to-Hagané, 47 (1961), 687.

4) I. Muchi and J. Higuchi: Tetsu-to-Hagané, 56 (1970), 371.
5) F. R. Block: Arch. Eisen., 43 (1972), 83.

6) M. Wajima and H. Soma: Tetsu-to-Hagané, 73 (1987), 1948.

7) M. Horio, T. Ootake and I. Muchi: Tetsu-to-Hagané, 60 (1974), 465.

8) H. B. Wendeborn: J. Iron Steel Inst., 175 (1953), 280.

9) Y. Shimomura: Fuji-Seitetsu-Giho, 10 (1960), 219.

10) Y. Fukagawa, Y. Ishikawa, N. Noguchi and M. Tateoka: Tetsu-toHagané, 50 (1964), 338.

11) T. Kawaguchi: ISIJ Int., 28 (1988), 705.

12) ISIJ: Tekko-Binran Vol. 1, ISIJ, Tokyo, (1981), 89. 